\title{
Tribochemistry of Bulk Zinc Metaphosphate Glasses
}

\section{Journal Article}

Author(s):

Crobu, Maura; Rossi, Antonella; Mangolini, Filippo; Spencer, Nicholas D.

Publication date:

2010-08

Permanent link:

https://doi.org/10.3929/ethz-b-000156379

Rights / license:

In Copyright - Non-Commercial Use Permitted

Originally published in:

Tribology Letters 39(2), https://doi.org/10.1007/s11249-010-9622-4 


\title{
Tribochemistry of Bulk Zinc Metaphosphate Glasses
}

\author{
Maura Crobu • Antonella Rossi · Filippo Mangolini • \\ Nicholas D. Spencer
}

Received: 30 March 2010/ Accepted: 6 May 2010/Published online: 23 May 2010

(C) Springer Science+Business Media, LLC 2010

\begin{abstract}
Zinc polyphosphate glasses are the principal component of the antiwear tribofilms formed on steel surfaces in the presence of additives, such as zinc dialkyldithiophosphates. In this work, amorphous, zinc metaphosphate glasses have been synthesized and characterized by means of X-ray diffraction (XRD), Fourier-transform infrared spectroscopy (FT-IR), elemental analysis, and X-ray photoelectron spectroscopy (XPS). Tribological tests were performed by rubbing steel balls against the zinc metaphosphate discs in a poly- $\alpha$ olefin (PAO) bath at room temperature. XPS was used in order to characterize the tribostressed areas on both metaphosphate discs and steel balls. A transfer film, constituted of iron and zinc polyphosphates, was formed on the contact area of the balls. This transfer film was found to reduce friction and prevent ball wear. A reduction in the relative intensities of XPS signals related to bridging-oxygen species and a binding energy shift of $0.4 \mathrm{eV}$ of the P $2 \mathrm{p}$ toward lower values demonstrated the presence of shorter-chain-length phosphates inside the tribo-tracks on the discs. Furthermore, iron was transferred to the glass during the tribological tests. A tribochemical reaction between zinc metaphosphate and iron oxide
\end{abstract}

M. Crobu · A. Rossi · F. Mangolini · N. D. Spencer $(\square)$ Laboratory for Surface Science and Technology, Department of Materials, ETH Zurich, Wolfgang-Pauli-Strasse 10, 8093 Zurich, Switzerland

e-mail: spencer@mat.ethz.ch

A. Rossi

Dipartimento di Chimica Inorganica ed Analitica, Università degli Studi di Cagliari, INSTM Unit - Cittadella Universitaria di Monserrato, 09100 Cagliari, Italy has been proposed as an explanation for the depolymerization of the glass and the formation of iron phosphate.

Keywords Antiwear additives - Boundary lubrication · Polyphosphate glasses - Tribochemistry .

$\mathrm{X}$-ray photoelectron spectroscopy (XPS)

\section{Introduction}

Polyphosphate glasses have been found to be responsible for the good antiwear properties of the tribofilms formed in the presence of phosphorus-based additives. Among them, zinc dialkyldithiophosphate (ZnDTP) is the most successful and widely used engine-oil additive. Its actual antiwear mechanism is only partially understood despite extensive research in recent decades. Interest in polyphosphate glasses has been recently stimulated by the need for more environmentally friendly replacements for ZnDTP, whose degradation products poison automobile exhaust catalysts and are thus harmful for the environment $[1,2]$.

The composition of tribofilms formed under sliding conditions on steel substrates in the presence of $\mathrm{ZnDTP}$ has been extensively investigated. Underneath a viscous layer, which is easily removed by solvent washing, a film consisting of amorphous zinc and/or iron polyphosphates is formed [3-7]. This tribofilm has a layered structure: at the bottom a short-chain-length polyphosphate layer is present, intergrown with the iron oxide film. The top layer is thinner and formed by long-chain-length polyphosphates $[3,4]$. Since it is unlikely that there is a clear interface between the different layers, but a gradual transition [5], ZnDTP tribofilms are often described as containing a gradient in composition. ZnDTP tribofilms 
have been shown to respond to different tribological conditions by changing their physical properties. This ability, which has contributed to their success in applications, can also explain the apparent disagreement in the literature on the exact thickness, structure, and chemistry of the films. The mechanism of formation of the tribofilms is still unclear [1]: at room temperature ZnDTP molecules weakly interact with the steel surface, but, under sliding conditions, the additive reacts and forms a thin tribofilm [6]. The effect of temperature and applied pressure on the thickness and chemistry of the films formed under tribological conditions in the boundarylubrication regime has been recently investigated in our group: increasing the temperature induces the formation of longer polyphosphates and thicker films, while the application of higher pressures leads to shorter polyphosphate chain lengths and to an increase in the film thickness [7, 8]. Some authors have observed a shortening of the polyphosphate chains within the tribological scars as a consequence of rubbing [7,9]. The origin of the gradient of composition in the tribofilms and the role potentially played in its antiwear mechanism is still under debate. In 1999, Martin proposed a model based on the principle of hard and soft acids and bases (HSAB). According to this principle, first proposed by Pearson [10], the reaction between long-chain zinc polyphosphates and iron oxides to give shorter-chain length iron/zinc polyphosphate is energetically favorable [11]. Based on this model, Minfray proposed that the reaction occurring during friction between polyphosphates and iron oxide plays a double role: not only would it allow the digestion of abrasive iron oxide particles, but it would also provide a strong adhesion of the tribofilms to the substrate through chemical bonding [12].
With this cross-linking theory supported by molecular dynamics simulation, Müser proposed a possible alternative mechanism. According to this theory, pressure would be able to induce cross-linking in a phosphate network leading to a highly connected network with improved mechanical properties [13]. The model has not yet been supported by experimental evidence.

Despite enormous efforts made by researchers, who have applied almost every available surface-analytical technique, several open questions about the antiwear mechanisms of ZnDTP remain to be addressed. The study of model systems of ZDTP tribofilms, such as polyphosphates, has been considered in order to reduce the complexity of real systems. Gauvin tested the behavior of pure zinc orthophosphate powder as an antiwear additive. Under boundary-lubrication conditions, the orthophosphate formed an adherent film on the steel substrate. This film was found to reduce wear [14].

The technical applications of polyphosphates glasses are various. They are implemented in the formulation of ceramic restorative cements [15] and more generally of bioactive functional materials [16]. They possess many useful optical properties and have been widely employed as active elements in laser engineering [17, 18]. The hope to understand the antiwear mechanism of phosphorus-based additives renewed the interest of researchers in investigating the mechanical and tribological properties of zinc and iron polyphosphates themselves.

Condensed phosphates are formed by repeated condensation of tetrahedral $\mathrm{PO}_{4}$ groups, which, by linking through covalent bridging oxygen (BO) atoms, can share their corners with neighboring tetrahedra. The tetrahedra can be classified by the number of BOs $(\mathrm{P}-\mathrm{O}-\mathrm{P})$ per tetrahedron $\left(\mathrm{Q}_{i}\right.$ terminology, see Scheme 1$)$. The vitreous $\mathrm{P}_{2} \mathrm{O}_{5}$ is
Scheme 1 Terminology for different composition and structures in polyphosphate glasses
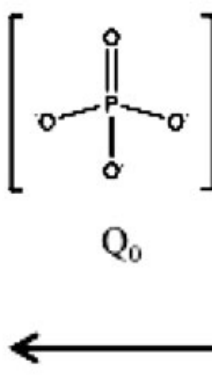

\section{Orthophosphate}

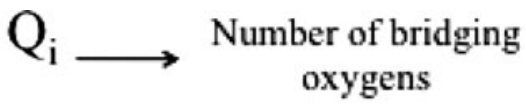<smiles>CC(C)(C)OP(=O)([O-])O</smiles><smiles>CC(C)(C)OP(=O)(O)OC(C)(C)C</smiles>

$\mathrm{Q}_{2}$<smiles>COP(=O)(OC)OC(C)(C)C</smiles>

Metal oxide content

Chain length

Pyrophosphate Metaphosphate

$\mathrm{P}_{2} \mathrm{O}_{5}$

Polyphosphate 
formed by a cross-linked network of $\mathrm{Q}_{3}$ tetrahedra. When a modifying oxide is added to $\mathrm{P}_{2} \mathrm{O}_{5}$ the network is depolymerized and the concentration of $\mathrm{Q}_{i}$ tetrahedra depends on the glass composition (Scheme 1) [19, 20]. In other words, depending on the oxygen-to-phosphorus ratio $([\mathrm{O}] /[\mathrm{P}])$ the number of tetrahedral linkages through BO atoms changes and thus a wide range of compositions and structures is possible [21].

In the last 50 years, several techniques have been used to investigate the short- and long-range order of these glasses. The coordination of metal cations has been studied by means of ${ }^{31} \mathrm{P}$ MAS-NMR, as well as neutron and X-ray diffraction (XRD) [22-26]. High-performance-liquidchromatography (HPLC) has been used in order to determine the distribution of phosphate-anion chains and rings and to provide detailed information about the structure. The results obtained for zinc polyphosphate glasses showed that the average chain length can be computed directly from the glass composition when the presence of ring anions can be neglected [27]. In the region of the metaphosphate composition, long-chain structures are mainly found, while cross-linked chains and rings, typical of the ultraphosphate region, disappear [28]. At higher concentrations of $\mathrm{ZnO}$ a depolymerization of the phosphate network is observed and the long chains are transformed into trimers, dimers, and monomers, as the composition approaches orthophosphate.

X-ray photoelectron spectroscopy (XPS) has been used to analyze the short-range structure of polyphosphate glasses. Gresch [29] studied sodium phosphate glasses and found that two different signals can be resolved in the XPS spectra: at higher binding energy the signal of the $\mathrm{BO}$, which links two phosphate groups together (P-O-P), and at lower binding energy the signal of the non-bridging oxygen (NBO), which terminates the phosphate $\left(-\mathrm{PO}_{x}\right)$. Moreover, their intensity ratio is directly proportional to the composition of the glass. Iron-, zinc- and boron-containing phosphate glasses have been investigated by Brow [30, 31].

More recently X-ray absorption near-edge structure (XANES) spectroscopy was also used to distinguish between polyphosphates with different chain lengths: the P L-edge XANES spectra are sensitive to the structural changes caused by the bridging $\mathrm{P}-\mathrm{O}$ bonds [32].

In this work, a sample-preparation protocol that allows the reproducible synthesis of zinc metaphosphate glasses for tribological testing has been established. The samples were characterized by means of XRD, FT-IR, elemental analysis, and XPS. The tribological tests were then performed by sliding steel balls on the metaphosphate discs. Light microscopy and profilometry were used in order to assess the wear behavior of the glasses, while the surface chemistry of the tribostressed balls and discs was investigated by means of XPS.

\section{Experimental}

\subsection{Synthesis of the Glasses}

Different chain length zinc polyphosphates were synthesized starting from stoichiometric mixtures of ammonium dihydrogen phosphate (Acros Organics, 99.9\% extra pure) and zinc oxide (Alfa Aesar, 99.9\%). The reaction for zinc metaphosphate is described in the following as an example:

$2 \mathrm{NH}_{4} \mathrm{H}_{2} \mathrm{PO}_{4}+\mathrm{ZnO} \rightarrow 3 \mathrm{H}_{2} \mathrm{O}+2 \mathrm{NH}_{3}+\mathrm{Zn}\left(\mathrm{PO}_{3}\right)_{2}$

The reagents in powder form were melted in alumina crucibles (high-density alumina produced by Metoxit AG, Thayngen, Switzerland) at $1,473 \mathrm{~K}$ in a RHF $16 / 3$ furnace (Carbolite ${ }^{\circledR}$, Hope Valley, UK) and then quenched in a copper tray that had been previously cooled to $253 \mathrm{~K}$. The samples obtained were clear and transparent, in the shape of round discs of $2-3 \mathrm{~cm}$ in diameter and 3-4 $\mathrm{mm}$ in thickness. After quenching, the samples were annealed at $623 \mathrm{~K}$ for $5 \mathrm{~h}$ in order to reduce internal stresses.

\subsection{Characterization of the Glasses}

XRD was used in order to ascertain that the samples were amorphous. The analyses were performed using a powder diffractometer STOE STADI P (STOE \& Cie GmbH, Darmstadt, Germany) equipped with an image-plate detector and a $\mathrm{Cu} \mathrm{K}-\alpha \mathrm{X}$-ray source.

The microelemental analysis for oxygen was carried out by means of a RO-478 (Leco Corporation, St. Joseph, MI, USA). The phosphorus content was determined by the molybdovanadate method after microwave digestion and subsequent leaching $(2 \times 50 \mathrm{~min})$ in concentrated sulfuric acid and perchloric acid at 483 and $508 \mathrm{~K}$.

Transmission FT-IR spectra were acquired with a Nicolet $^{\mathrm{TM}} 5700$ Fourier-transform infrared spectrometer (Thermo Electron Corporation, Madison, WI, USA). The experimental conditions are shown in Table 1. The glasses were ground with dried $\mathrm{KBr}$ and pressed into a pellet. The spectra were processed with OMNIC ${ }^{\mathrm{TM}}$ software (V7.2, Thermo Electron Corporation, Madison, WI, USA). A single-beam spectrum of a bare $\mathrm{KBr}$ pellet was acquired before each measurement as a background spectrum.

Table 1 Transmission FT-IR experimental conditions

\begin{tabular}{ll}
\hline Detector & DGTS/KBr \\
\hline Resolution & $2 \mathrm{~cm}^{-1}$ \\
Number of scans & 64 \\
Scan velocity & $0.6329 \mathrm{~cm} / \mathrm{s}$ \\
Acquisition time & $136 \mathrm{~s}$ \\
Gain control & 1 \\
\hline
\end{tabular}




\subsection{Mechanical Polishing}

Prior to the tribological tests, the samples were mechanically polished. Grinding was performed using P320, P600, P1200, and P2400 silicon carbide paper (Presi, Grenoble, France). The polishing was then performed using 3 and $1 \mu \mathrm{m}$ diamond paste on polishing cloths (Struers $\mathrm{GmbH}$, Birmensdorf, Switzerland). The average surface roughness (Ra) was measured by AFM and found to be $4.0 \pm 0.2 \mathrm{~nm}$. Ethanol was always used as a polishing lubricant, in order to remove the heat produced by friction and to avoid chemical changes at the surface. The samples were then kept in an ultrasonic bath in ethanol for 10 min prior to the tests.

The mechanically polished samples were characterized by XPS.

\subsection{Tribological Tests}

The tribological tests were carried out by means of a CETR UMT-2 tribometer with a ball-on-disk set-up. The load cell had a maximum load of $20 \mathrm{~N}$ and a resolution of $1 \mathrm{mN}$ in two axes: normal load and friction force. 100Cr6 steel balls (6-mm diameter) were rubbed against the zinc metaphosphate polished discs. The roughness of the balls was characterized by means of a white-light profilometer (Sensofar PLu Neox, Sensofar-Tech SL., Terrassa, Spain) and was found to be $0.277 \pm 0.003 \mu \mathrm{m}$. The tests were performed at room temperature in pure polyalphaolefin (PAO, Durasyn ${ }^{\circledR}$ 166, Tunap Industrie $\mathrm{GmbH} \& \mathrm{Co}$, Mississauga, Canada) at two different loads, 5 and $7 \mathrm{~N}$, with a constant sliding speed of $30 \mathrm{~mm} / \mathrm{min}$. Lubricated, rather than dry conditions were chosen, so as to resemble the rheological and heat transfer properties of a metalmetal lubricated contact. Four concentric wear tracks, separated from each other by $0.75 \mathrm{~mm}$, were obtained on each disc. In order to achieve a conformal and reproducible flat on the ball, the running-in was performed on a $100 \mathrm{Cr} 6$ steel disc at $10 \mathrm{~N}$ and $300 \mathrm{~mm} / \mathrm{min}$ for $2 \mathrm{~h}$ in the presence of pure PAO. Before the analysis balls and discs were cleaned in an ultrasonic bath for $10 \mathrm{~min}$ in $n$-hexane and gently wiped with a tissue paper. The tribostressed balls and discs were then examined with the aid of a light microscope.

\subsection{XPS and Imaging-XPS}

The XPS analyses were performed by means of a PHI Quantera SXM spectrometer (ULVAC-PHI, Chanhassen, MN, USA) equipped with an Al K $\alpha$ monochromatic source whose beam size ranges from 5 to $200 \mu \mathrm{m}$. The Gauze input lenses collect the photoelectrons at an emission angle of $45^{\circ}$ and direct them through the high-resolution spherical capacitor analyzer to the 32-channel detector system. The spectrometer is also equipped with a lowvoltage argon ion gun and a sample neutralizer for charge compensation. The calibration was performed using sputter-cleaned gold, silver, and copper as reference materials according to ISO15472:2001. The accuracy was found to be $\pm 0.1 \mathrm{eV}$. All the experiments were run at residual pressures below $5 \times 10^{-7} \mathrm{~Pa}$. Binding-energy values are reported in this work as means over three or more independent measurements with their corresponding standard deviations.

Survey spectra were acquired in fixed analyzer transmission (FAT) mode using a pass energy (PE) of $280 \mathrm{eV}$, while the high-resolution spectra were collected with a $\mathrm{PE}$ of $26 \mathrm{eV}$; the full width at half maximum of the peak height, FWHM, of the silver Ag $3 \mathrm{~d}_{5 / 2}$ signal for high-resolution spectra was $0.62 \mathrm{eV}$. The beam diameters used were 100 and $20 \mu \mathrm{m}$, depending on the size of the feature analyzed. X-ray excited secondary electron images (SXI) were used in order to determine the topography and, thus, to be able to collect small area XPS spectra from the features present on the sample. When analyzing the glass discs the electron neutralizer was used in order to compensate for sample charging and the spectra were further corrected with reference to adventitious aliphatic carbon at $285.0 \mathrm{eV}$.

Imaging-XPS (i-XPS) was performed with a beam size of $20 \mu \mathrm{m}$ and a PE of $140 \mathrm{eV}$ in snapshot mode; in these conditions the spectra were acquired over a BE range of $15.5 \mathrm{eV}$. The area of the maps was $600 \times 600 \mu \mathrm{m}^{2}$ and required 1-2 $\mathrm{h}$ of acquisition per map. Maps of the carbon signal, C 1s, were acquired in order to exclude the possibility of localized sample charging.

The spectra were processed using CasaXPS software (version 2.3.15, Casa Software Ltd, Wilmslow, Cheshire, UK). The background subtraction was performed using the Shirley-Sherwood iterative method. The product of Gaussian and Lorentzian functions was used for curve fitting. The maps were processed using Multi-Pak ${ }^{\mathrm{TM}}$ software (version 8.1c, ULVAC-PHI, Chanhassen, MN, USA).

The quantitative analysis was performed using the firstprinciples method valid for homogeneous samples [33]. The area of the peaks assigned to each component $\mathrm{A}$ is proportional to the atomic concentration after correcting for the sensitivity factor, calculated as follows:

$s_{\mathrm{A}}=\sigma_{\mathrm{A}}(h v) \cdot \Lambda_{\mathrm{MA}} \cdot L_{\mathrm{A}}(\gamma) \cdot T\left(E_{\mathrm{A}}\right)$,

where $\sigma$ is the Scofield photoelectric cross-section [34], $L_{\mathrm{A}}$ is the asymmetry parameter, calculated according to [35], and $T$ is the analyzer transmission function. The inelastic mean free path, $\Lambda$, was calculated using the TPP$2 \mathrm{M}$ formula [36] as a function of the material characteristics. 


\section{Results}

\subsection{Characterization of Zinc Metaphosphate}

The samples were characterized by XRD. All the samples investigated presented a broad peak, characteristic of amorphous compounds as shown in Fig. 1a.

The phosphorus content was determined by microelemental analysis and found to be $27.6 \pm 0.1 \mathrm{wt} \%$ (the expected value for the phosphorus content was $27.7 \mathrm{wt} \%$ ).

The transmission FT-IR spectrum of the prepared glassy zinc metaphosphate is shown in Fig. 1b. Similarly to the FT-IR spectra of vitreous phosphate glasses with different compositions reported in the literature [37-40], the vibrational spectrum of amorphous zinc metaphosphate is characterized by complex peak shapes. The asymmetric peak between 1350 and $1200 \mathrm{~cm}^{-1}$ with a maximum at $1270 \mathrm{~cm}^{-1}$ can be assigned to the $v_{\text {as }}\left(\mathrm{PO}_{2}^{-}\right)$of the $\mathrm{Q}_{2}$ units and to the $v(\mathrm{P}=\mathrm{O})$ of the $\mathrm{Q}_{3}$ units $[38,40,41]$. In the region between 1050 and $1150 \mathrm{~cm}^{-1}$ the characteristic stretching mode of the $\mathrm{Q}_{1}$ units $\left(v_{\mathrm{as}}\left(\mathrm{PO}_{3}^{2-}\right)\right)$, which is usually very intense in IR spectra, was not detected, indicating that the phosphate tetrahedral structure did not undergo any disproportionation reaction as reported in [40].

In Fig. 2, the XPS spectra acquired on the as-received samples are shown. The samples were introduced into the spectrometer immediately after the synthesis, in order to minimize contamination from the lab environment. The survey spectra show a very low intensity carbon peak, which confirms that the level of contamination is very low, and aluminum is also present in trace amounts. In the $\mathrm{O} 1 \mathrm{~s}$ high-resolution spectrum two components are resolved with two peaks at $532.3 \pm 0.1 \mathrm{eV}$ and $533.9 \pm 0.1 \mathrm{eV}$. The peak at lower binding energy can be assigned to the $\mathrm{NBO}$, while the second peak has to be assigned to the $\mathrm{BO}$ (see Scheme 2). Previous studies have shown that the intensity ratio $\mathrm{BO} / \mathrm{NBO}$ is directly correlated with the average chain length [31]. For the metaphosphate composition the theory predicts an infinite chain length with a corresponding $\mathrm{BO} / \mathrm{NBO}$ of 0.5 . In this work, the experimental $\mathrm{BO} / \mathrm{NBO}$ was found to be $0.45 \pm 0.05$, in good agreement with the expected value. The phosphorus $\mathrm{P} 2 \mathrm{p}_{3 / 2}$ was found at $134.7 \pm 0.1 \mathrm{eV}$, the $\mathrm{Zn} 3 \mathrm{~s}$ at $140.9 \pm 0.1 \mathrm{eV}$ and the $\mathrm{Zn} 2 \mathrm{p}$ at $1022.7 \pm 0.1 \mathrm{eV}$. Since the average is proportional to the $\mathrm{ZnO}$ to $\mathrm{P}_{2} \mathrm{O}_{5}$ ratio, the corrected intensity $\mathrm{P} / \mathrm{Zn}$ ratio can also be used as quantitative information on the glass composition. In our case, the $\mathrm{P} / \mathrm{Zn}$ ratio on the as-received samples was found to be $2.3 \pm 0.5$, while the stoichiometric ratio would be 2 . The composition of the glass calculated by means of the first-principles method is shown in Table 2.

\subsection{Characterization of Zinc Pyrophosphate and Zinc Orthophosphate}

Zinc pyrophosphate and zinc orthophosphate were also synthesized and characterized, as for the metaphosphate case. The XRD results showed that the orthophosphate could only be obtained in the crystalline form, while the pyrophosphate was amorphous.

Information on the composition of the samples was obtained by elemental analysis and XPS; the results are summarized in Table 2.

The $\mathrm{BO} / \mathrm{NBO}$ ratio and the $\mathrm{P} 2 \mathrm{p} 3 / 2$ binding energies for all the polyphosphate compositions are shown in Table 3 . With increasing $\mathrm{Zn}$ content the chain length of the glass decreases. A lower BO/NBO ratio corresponds to shorter chain lengths, moreover a chemical shift toward lower binding energies is observed in the P $2 \mathrm{p}$ signal moving from longer to shorter chains.

All the FT-IR spectra were found to be in good agreement with the literature.
Fig. 1 Characterization of the amorphous zinc metaphosphate samples: (a) X-ray diffraction spectrum; (b) transmission FT-IR spectrum
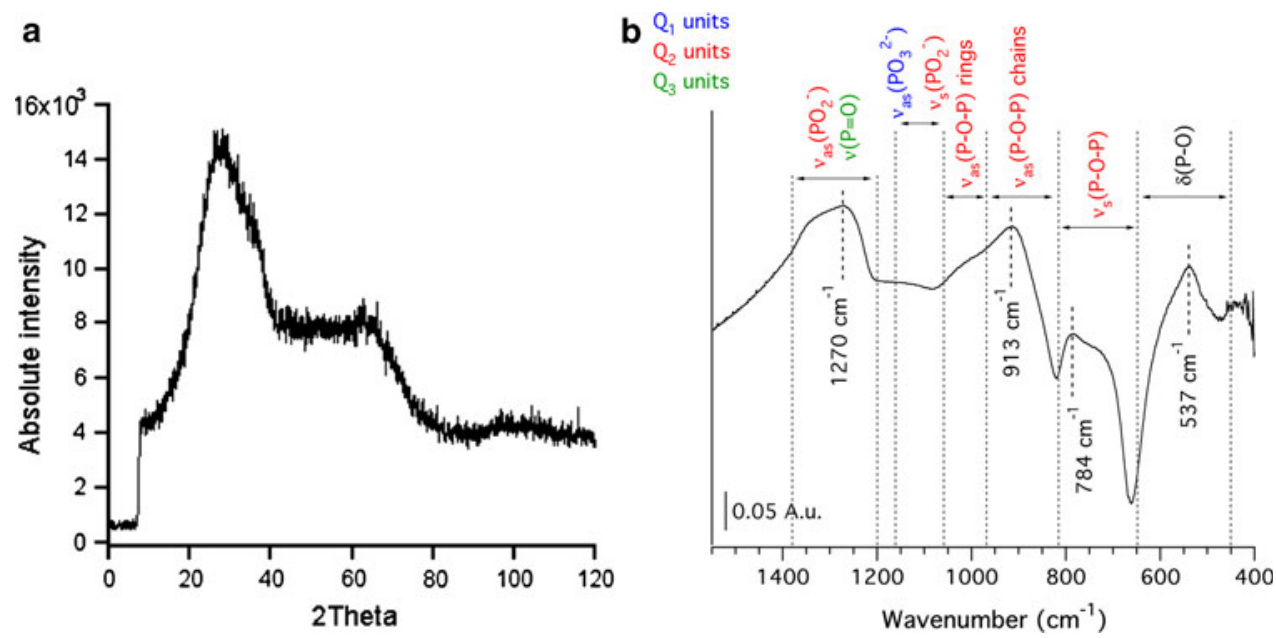
Fig. 2 XPS high-resolution spectra of O 1s, P 2p, Zn 3s, Zn $2 p$ signals and survey spectrum acquired on as received zinc metaphosphate

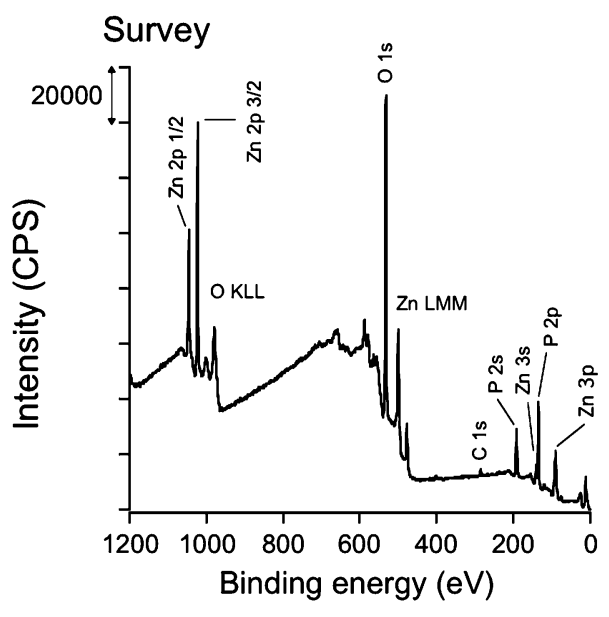

Phosphorus $2 p$ and Zinc $3 s$

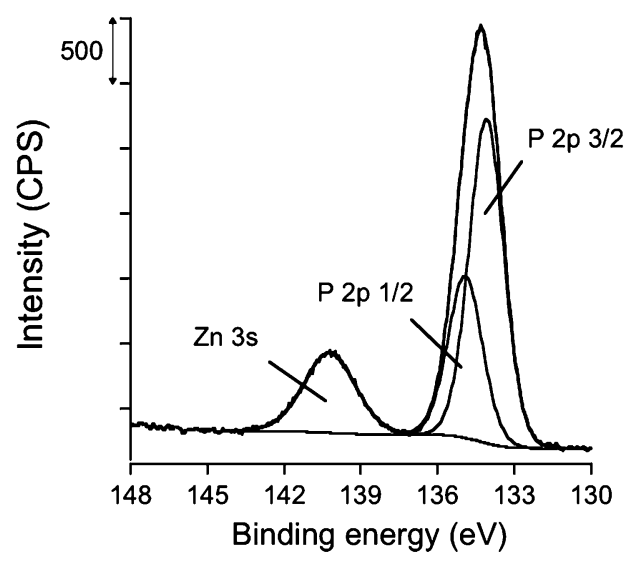

Oxygen 1s

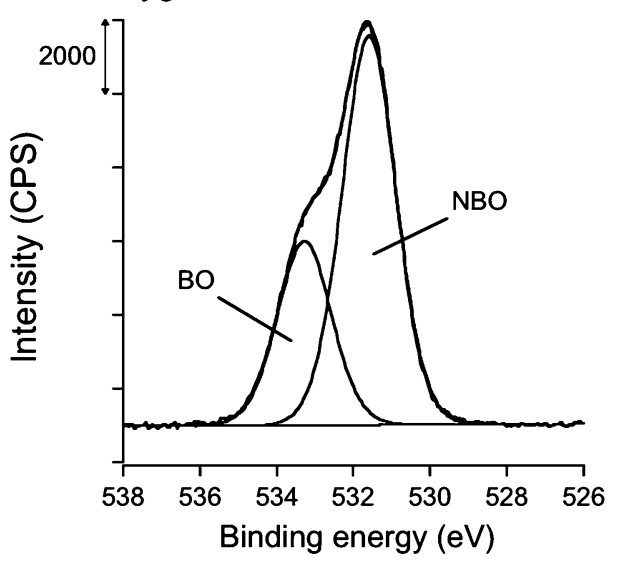

Zinc 2p

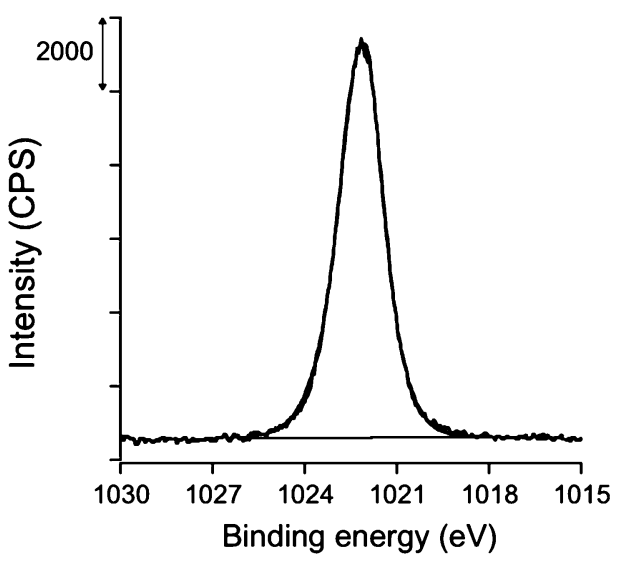

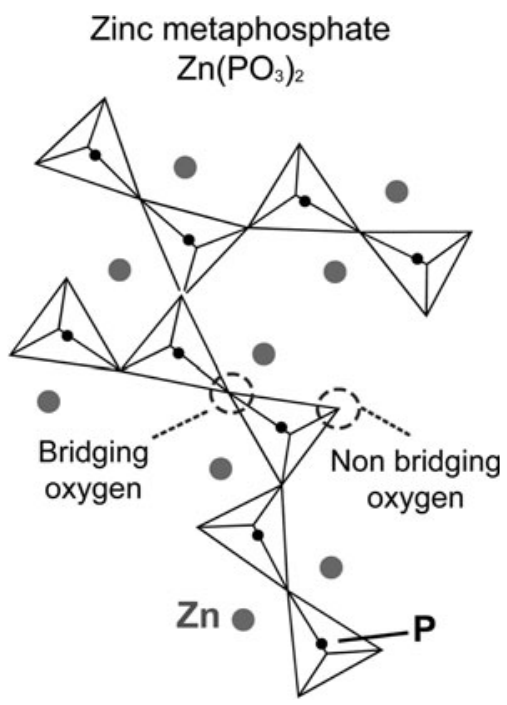

Scheme 2 Schematic representation of the zinc metaphosphate structure

\subsection{Friction and Wear}

In Fig. 3, the values of the coefficient of friction at two different loads for steel-versus-steel and steel-versus-zinc- metaphosphate tribopairs are shown. No significant changes of the friction were observed during a 2-h test. Since the coefficient of friction did not exhibit any change with sliding time, the average coefficient of friction values were calculated and are shown in Fig. 3. The coefficient of friction was always lower in the case of the steel-versuszinc-metaphosphate tribopair. The wear coefficient of the balls was calculated from the flattened area on top of the balls, which was measured by means of optical microscopy. The dimensional wear coefficient was then calculated as worn volume divided by load and sliding distance (Fig. 4). The contact pressures were calculated and found to be around $200 \mathrm{MPa}$ for the steel-versus-steel and $300 \mathrm{MPa}$ for the steel-versus-metaphosphate tribopair. Compared to the steel-versus-steel tribopair, which does not exhibit any dependence of the wear coefficient with the applied load, lower values were obtained for the steelversus-metaphosphate tribopair with the lowest value for the experiment performed at $5 \mathrm{~N}$. The tribotracks on the discs were investigated with the light microscope: both the metallic samples appeared drastically damaged while, on the other hand, on the zinc metaphosphate samples the damage was very limited for both the investigated loads. 
Table 2 Characterization of zinc polyphosphates of different chain lengths

\begin{tabular}{llll}
\hline & Zinc metaphosphate & Zinc pyrophosphate & Zinc orthophosphate \\
\hline XRD & Amorphous & Amorphous & Crystalline \\
Elemental analysis & {$[\mathrm{P}]=27.6 \pm 0.1 \mathrm{wt} \%$} & {$[\mathrm{P}]=20.3 \pm 0.1 \mathrm{wt} \%$} & {$[\mathrm{P}]=16.1 \pm 0.1 \mathrm{wt} \%$} \\
XPS $^{\mathrm{a}}$ & {$[\mathrm{P}]=32 \mathrm{wt} \% ;$} & {$[\mathrm{P}]=23 \mathrm{wt} \% ;$} & {$[\mathrm{P}]=19 \mathrm{wt} \% ;$} \\
& {$[\mathrm{O}]=42 \mathrm{wt} \% ;[\mathrm{Zn}]=27 \mathrm{wt} \%$} & {$[\mathrm{O}]=36 \mathrm{wt} \% ;[\mathrm{Zn}]=41 \mathrm{wt} \%$} & {$[\mathrm{O}]=33 \mathrm{wt} \% ;[\mathrm{Zn}]=48 \mathrm{wt} \%$} \\
\hline
\end{tabular}

${ }^{a}$ The maximum relative error in the quantitative analysis is $10 \%$

Table 3 BO/NBO ratios and $\mathrm{P} 2 \mathrm{p}$ 3/2 binding energies for the reference and the tribological samples

\begin{tabular}{lcclccc}
\hline & $\begin{array}{l}\text { Zinc ortho- } \\
\text { phosphate }\end{array}$ & $\begin{array}{l}\text { Zinc pyro- } \\
\text { phosphate }\end{array}$ & $\begin{array}{l}\text { Zinc } \\
\text { metaphosphate }\end{array}$ & $\begin{array}{l}\text { Mechanically polished } \\
\text { metaphosphate }\end{array}$ & $\begin{array}{l}\text { Metaphosphate after } \\
\text { tribological test } \\
\text { Non contact }\end{array}$ & $\begin{array}{l}\text { Metaphosphate after } \\
\text { tribological test } \\
\text { In contact }\end{array}$ \\
\hline $\mathrm{BO} / \mathrm{NBO}$ & 0.15 & 0.20 & 0.45 & 0.39 & 0.40 & 0.33 \\
$\mathrm{P} 2 \mathrm{p} 3 / 2 \mathrm{BE}$ & $134.1 \mathrm{eV}$ & $134.3 \mathrm{eV}$ & $134.7 \mathrm{eV}$ & $134.7 \mathrm{eV}$ & $134.7 \mathrm{eV}$ & $134.3 \mathrm{eV}$ \\
\hline
\end{tabular}

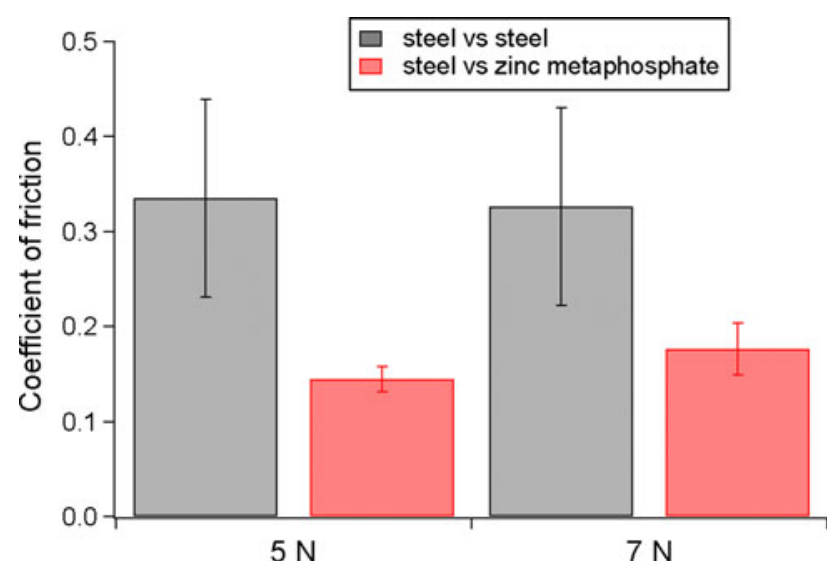

Fig. 3 Tribological results; comparison between steel-versus-steel and steel-versus-zinc-metaphosphate tribopairs

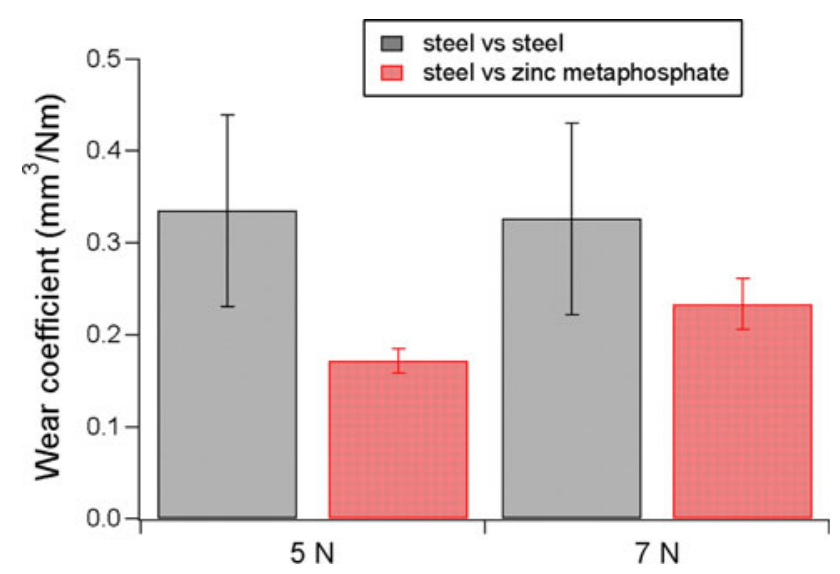

Fig. 4 Wear coefficient of the ball; comparison between steel-versussteel and steel-versus-zinc-metaphosphate tribopairs
The dark large spots visible in Fig. 5b, c can be attributed to the debris originated from the ball and transferred to the disc. The tests shown in Figs. 3 and 4 were run using a new ball for each new test on a different track. Some other tests were performed using one single ball (previously flattened during a running-in experiment) and moving it from one radius to the other on the same sample: a decrease in the friction with the order of the test, and independently on the applied load, was observed. These findings suggest that during sliding the chemistry on the surface ball is changing. This change is able to affect both friction and wear. This is the reason why, in order to obtain reproducible data, a new ball was used for every test.

\subsection{XPS Results}

\subsubsection{Analysis of the Balls}

Small-area XPS and i-XPS were used in order to characterize the balls after the tribological tests. The maps in Fig. 6 show the spatial distribution of the intensity of each element. For each pixel a complete spectrum was acquired, the calculated intensity of each spectrum corresponding to the color in the map. The oxygen $\mathrm{O}$ 1s signal was fitted using three different functions, one corresponding to the oxygen of the iron oxide at $530 \mathrm{eV}$, one to the $\mathrm{NBO}$ at $532.3 \mathrm{eV}$ (this component may also include iron oxides and hydroxides), and one to the $\mathrm{BO}$ at a $\mathrm{BE}$ of $1.6 \mathrm{eV}$ higher than the NBO peak. Three maps corresponding to the three chemical states were reconstructed using a linearleast-squares routine. The images show the presence of a uniform layer on the contact area, where zinc, phosphorus, bridging and non-bridging oxygen are present, while the signal of iron oxide is not detected. On the other hand, in 
Fig. 5 Light microscopy image of the wear track on the disc and the contact area on the ball for the steel-versus-steel tribopair at $5 \mathrm{~N}(\mathbf{a}, \mathbf{b})$ and $7 \mathrm{~N}(\mathbf{c}, \mathbf{d})$. Wear track on the disc and the contact area on the ball for the steelversus-zinc-metaphosphate tribopair at $5 \mathrm{~N}(\mathbf{e}, \mathbf{f})$ and $7 \mathrm{~N}$ $(\mathbf{g}, \mathbf{h})$
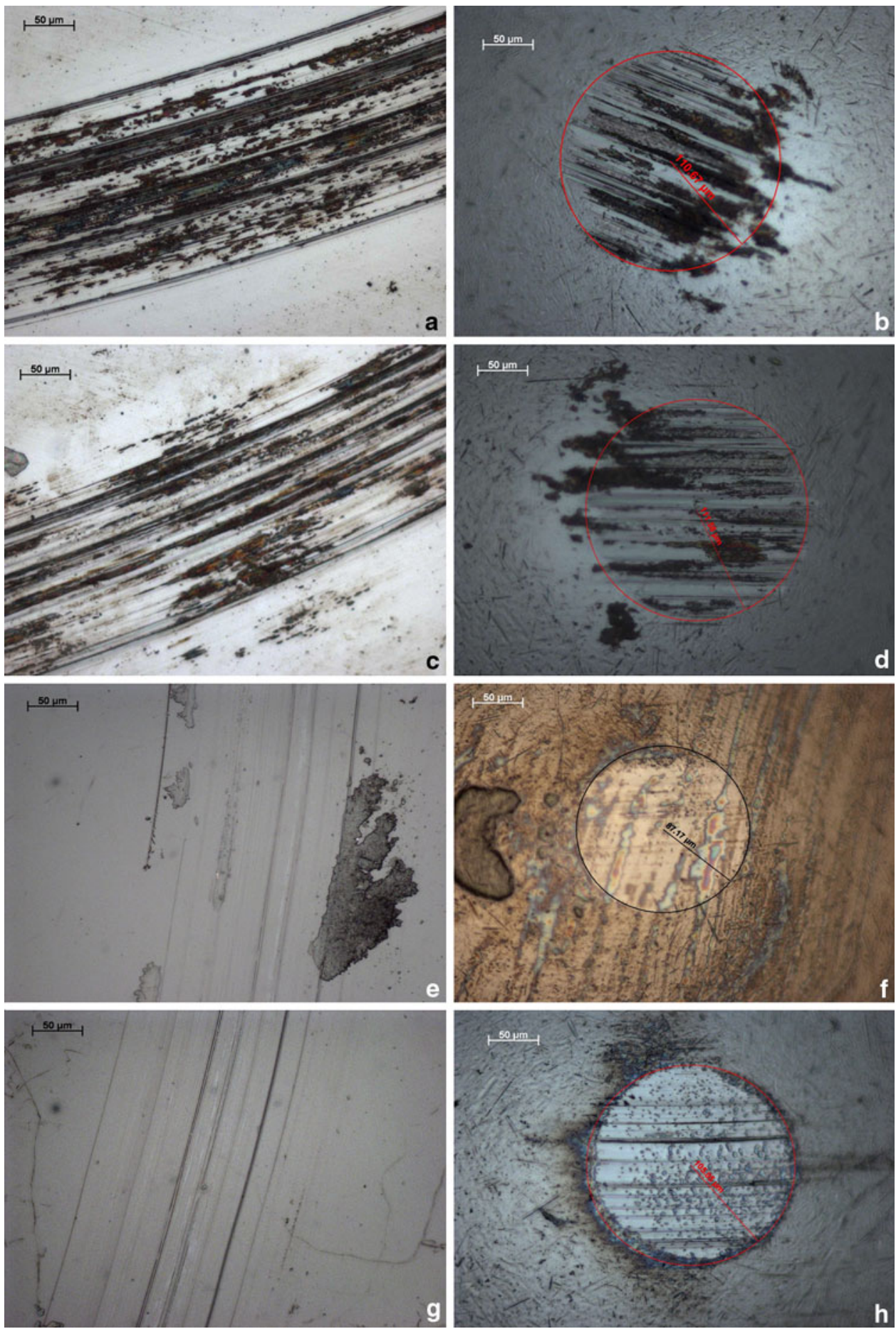

the non-contact region only the oxide and NBO signal are present. The diameter of the contact area in the chemical maps, around $150 \mu \mathrm{m}$ for the $5 \mathrm{~N}$ test as shown in Fig. 5, was comparable to that observed with the light microscope.

Small-area XPS was performed in three different locations: inside, outside, and at the border of the contact area (Fig. 7). Also in this case the $\mathrm{O} 1 \mathrm{~s}$ spectra were curve fitted with three components, i.e. oxide, $\mathrm{NBO}$, and $\mathrm{BO}$. In the $\mathrm{O}$ 1s spectra of the contact area only the $\mathrm{BO}$ and $\mathrm{NBO}$ components are present, while the oxide component is not detected. Inside the contact area the Fe $2 p$ signal (Fig. 7c) is completely attenuated: considering that $\lambda \cos (\theta)$ for the Fe 2 p peak is $2 \mathrm{~nm}$, it means that the glassy layer is at least thicker than $6 \mathrm{~nm}$. Since in this case hydroxides do not contribute to the NBO signal, the spectra can be used for 
Fig. 6 i-XPS on the ball following the tribotests. Each pixel on the map corresponds to a complete spectrum: the color is proportional to the intensity of the spectrum calculated as the area under the peak

\section{Ball after tribotest}

Zinc 2p 3/2

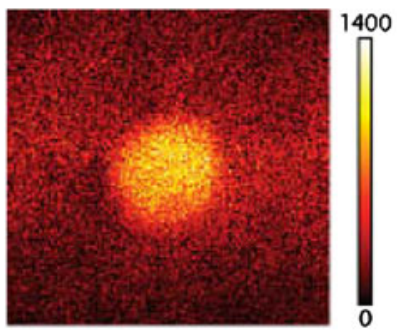

Oxygen 1s (NBO)

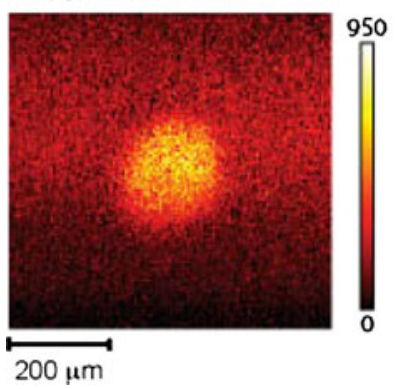

Phosphorus 2p

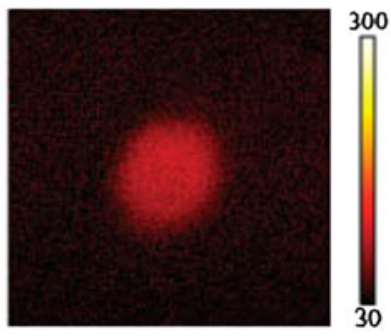

Oxygen 1s (BO)

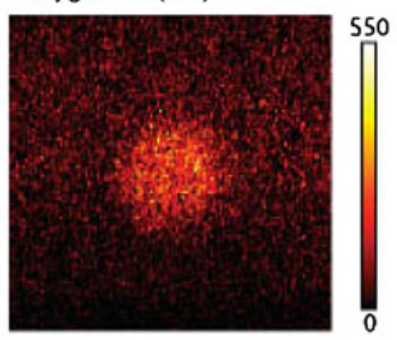

Oxygen 1s

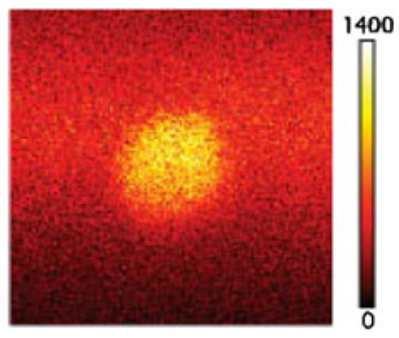

Oxygen 1s (Oxide)

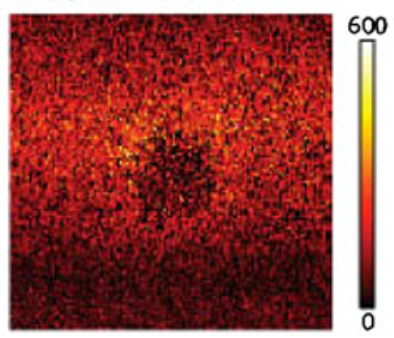

calculating the composition of the transfer film. Since the value of the $\mathrm{BO} / \mathrm{NBO}$ intensity ratio was 0.3 , it was possible to determine that the polyphosphate chain length was intermediate between a pyrophosphate and a metaphosphate.

The $\mathrm{O} 1 \mathrm{~s}$ spectrum acquired at the border of the contact area shows the presence of the iron oxide signal at lower $\mathrm{BEs}$, together with the $\mathrm{BO}$ and NBO signals. In this position the phosphorus peak is present with lower intensity, while neither the $\mathrm{Zn} 2 \mathrm{p}$ nor the $\mathrm{Zn} 3 \mathrm{p}$ signals could be detected.

In the non-contact region, the BO signal could no longer be detected.

The $\mathrm{P} 2 \mathrm{p}$ signal is intense in the contact area $\left(\mathrm{P} 2 \mathrm{p}_{3 / 2}\right.$ was found at $134.6 \pm 0.2 \mathrm{eV}$ ). In the border and out-ofcontact regions, however, this signal was very weak. The position of the $\mathrm{P} 2 \mathrm{p}_{3 / 2}$ is shifted toward lower BEs: $134.2 \pm 0.2 \mathrm{eV}$ at the border and $134.0 \pm 0.2 \mathrm{eV}$ in the out-of-contact region.

\subsubsection{Analysis of the Discs}

The wear tracks on the discs were characterized by i-XPS, and small-area XPS spectra were acquired both inside and outside the tribotracks. The $\mathrm{O} 1 \mathrm{~s}$ intensity map is shown in Fig. 8. As described in the previous paragraph, the $\mathrm{O} 1 \mathrm{~s}$ signal was curve fitted with the two characteristic signals of the polyphosphate glass: $\mathrm{NBO}$ at $532.3 \mathrm{eV}$ and $\mathrm{BO}$ at $533.9 \mathrm{eV}$. The intensity of the total oxygen is lower inside the tribotrack, with the $\mathrm{BO} / \mathrm{NBO}$ ratio being lower in the entire contact area (Fig. 9).
From the quantitative analysis of the small area XPS results (Fig. 8) a $\mathrm{BO} / \mathrm{NBO}$ ratio of $0.3 \pm 0.05$ was obtained in the contact area compared to the $0.4 \pm 0.05$ obtained in the non-contact area (same value obtained for the mechanically polished samples). The NBO signal is shifted from $532.4 \pm 0.1$ to $532.1 \pm 0.1 \mathrm{eV}$. Also the P $2 \mathrm{p}$ signal is shifted toward lower BEs: the signal was found at $134.7 \pm 0.1 \mathrm{eV}$ for the non-contact region and $134.3 \pm 0.2 \mathrm{eV}$ inside the tribotrack. These results suggest consequence of the tribological test (see also Table 3).

The iron $2 \mathrm{p}$ peak is detected within the tribotrack, indicating a transfer of iron from the ball to the disc. The chemical state of iron is a mixture of oxides, hydroxides and, possibly, phosphates.

\section{Discussion}

In this article, a protocol for the synthesis and testing of bulk amorphous zinc metaphosphate glasses has been proposed. The characterization results confirm the expected composition and structure of the samples. By means of a surface-sensitive analytical tool, XPS, it was possible to investigate the tribochemical reactions taking place under sliding conditions. Studying the effect of tribochemical reactions on the fully formulated tribofilms is a very complex analytical problem. The experiments described in this work have the unquestionable advantage of using a homogeneous and well-characterized sample as a starting point. that the glass is depolymerized within the contact area as a 
Fig. 7 Small-area XPS on the contact area of the ball after the tribotest

\section{Ball after tribotest}

Oxygen 1s

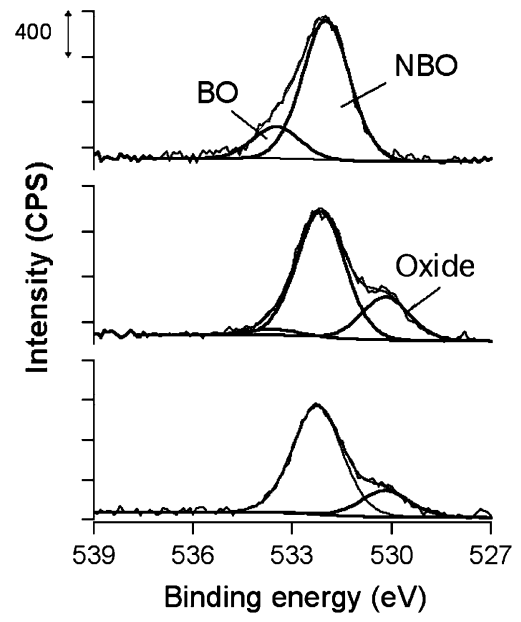

Zinc $2 p$

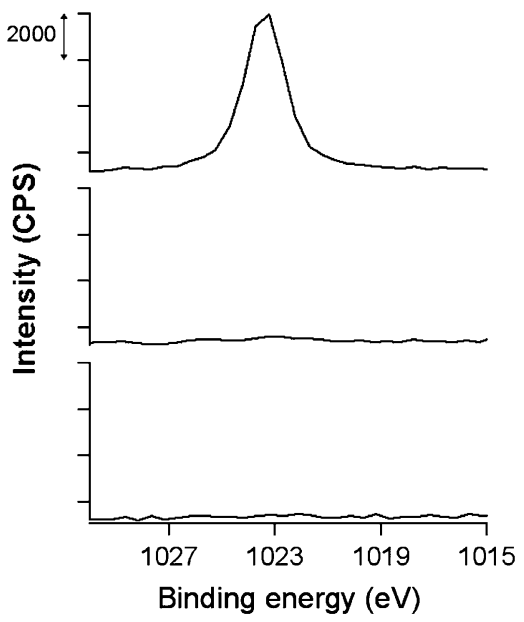

Phosphorus $2 p$ and Zinc 3s
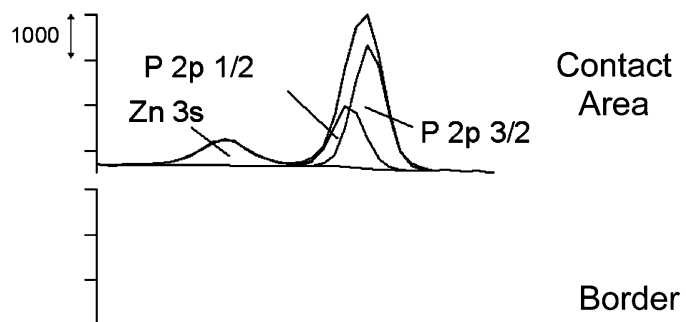

Non

Contact

Contact

Area

$200 \uparrow$

Iron $2 p$

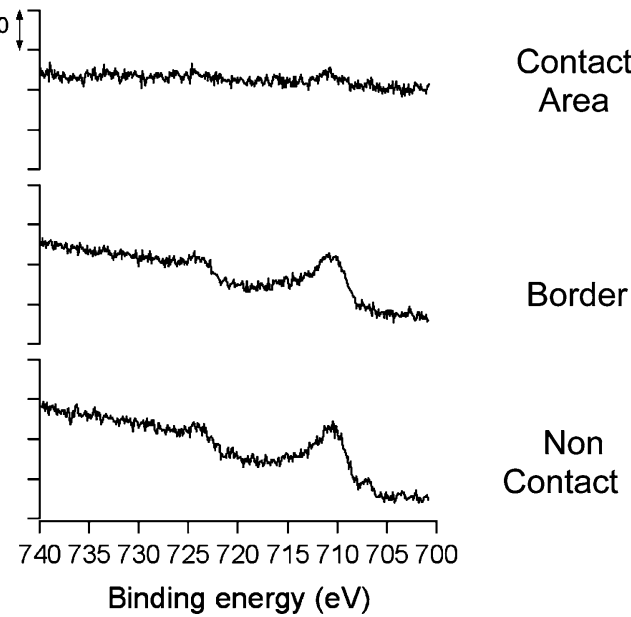

Fig. 8 i-XPS of the tribotrack on the zinc metaphosphate disc

\section{Zinc metaphosphate disc after tribotest}

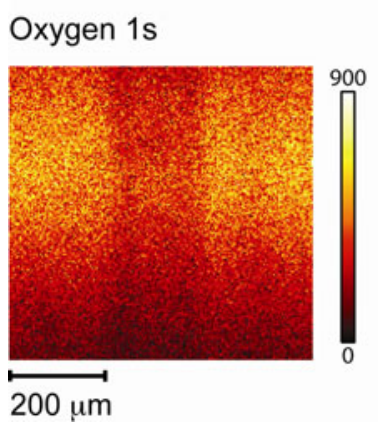

Oxygen 1s (BO)

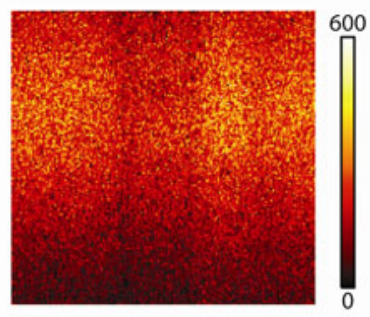

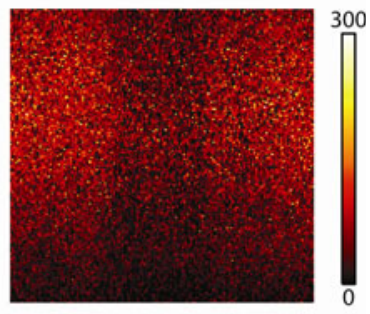

the $\mathrm{BO} / \mathrm{NBO}$ ratio and the $\mathrm{P} 2 \mathrm{p}_{3 / 2}$ binding energy $[6,8,19$, $42,43]$. Bridging and non-bridging oxygen are separated by approximately $1.6 \mathrm{eV}$ in binding energy. Thanks to the use of the monochromatic X-ray source, which provides an energy resolution of $0.63 \mathrm{eV}$ under these experimental 
Fig. 9 High-resolution spectra of the tribotrack on the zinc metaphosphate disc

\section{Zinc metaphosphate disc after tribotest}

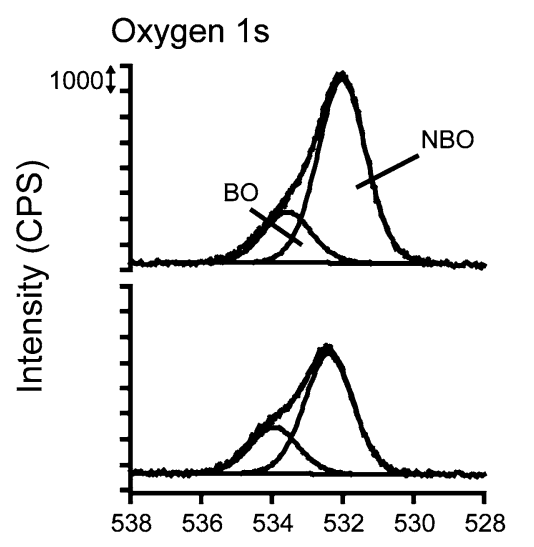

Phosphorus $2 p$ and Zinc 3 s

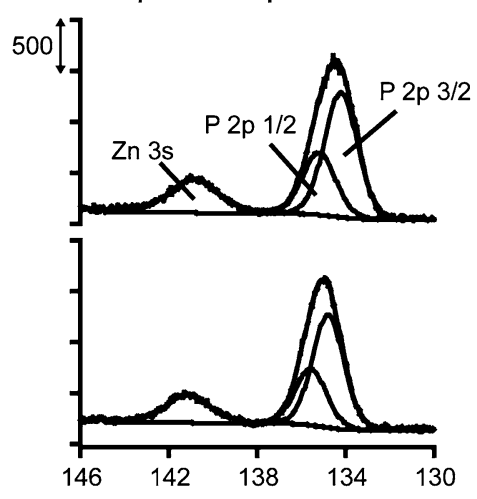

Out of contact

Iron $2 p$

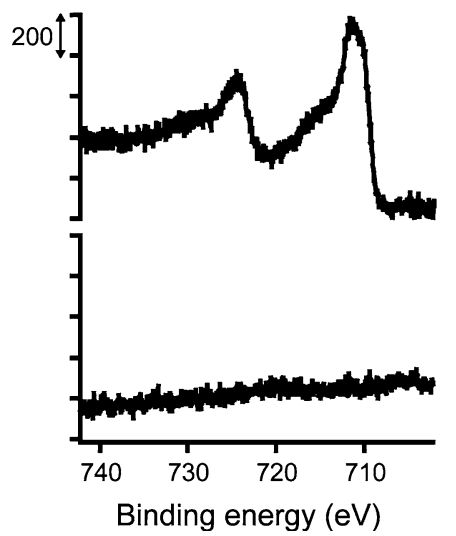

Contact area
Zinc 2p

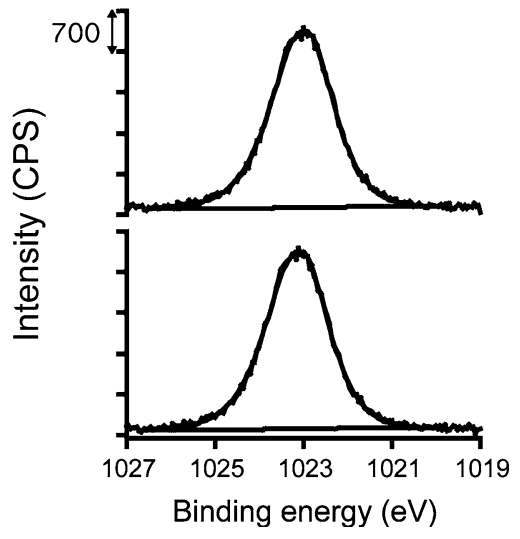

Contact area

Out of contact conditions, the two signals can be resolved and used for calculating the average chain length of the glass. The presence of contaminants on the glass surface turned out to strongly influence the quantitative analysis. Careful sample preparation and fast introduction into the UHV, which allowed the sample surface to be contamination-free and, as a consequence, the quantitative analysis to correspond to the expected composition, was found to be essential. The binding energy of the phosphorus $2 p$ signal, being sensitive to the chain length of the glass, provides further experimental support for the results obtained from the $\mathrm{BO}$ to NBO ratio. These tools, combined with the surface sensitivity of XPS, were used in this investigation in order to gain an insight into the chemical changes occurring at the surface of tribostressed samples.

\subsubsection{Analysis of the Ball: Composition of the Transfer Film}

The imaging-XPS of the ball shows a very clear contrast between the contact area and the non-contact area: a transfer film is present in the contact area and is mainly composed of zinc polyphosphates. The diameter of the transfer film, around $150 \mu \mathrm{m}$, is approximately the same as that of the flattened area on the ball. The detailed spectra acquired in the center of the contact area show the absence of an iron peak. Therefore, at this point the transfer film is thick enough to completely attenuate the iron peak (the layer is therefore thicker than $6 \mathrm{~nm}$ ). Also at this point the signal of the $\mathrm{O} 1 \mathrm{~s}$ spectrum at $530.0 \mathrm{eV}$, assigned to iron oxide, is absent; the two components used for the curve fitting correspond to the characteristic signals of polyphosphates, i.e., the $\mathrm{BO}$ and NBO peaks. The BO/NBO ratio was found to be 0.3 within the contact area. The average chain length is thus shorter than the metaphosphate composition of the disc before the tribological test. In the non-contact area the zinc signal and the $\mathrm{BO}$ signal are not detected: iron oxide is mainly present together with a very low-intensity phosphorus peak. At the border of the contact area a small peak assigned to the BO was detected together with the oxide peak, which means that a thinner layer of glass is present. However, neither of the zinc signals, Zn 2p and $\mathrm{Zn} \mathrm{3s}$, could be detected. The only possible cation in this case is iron, i.e., the presence of iron phosphate is indicated. Moreover the phosphorus peak is shifted toward lower BE values suggesting the presence of shorter chain 
lengths at the border of the area and, therefore, of a lateral compositional gradient in the transfer film.

\subsubsection{Analysis of the Disc: Composition in the Tribotracks}

The tribostressed area is clearly visible in the O 1s map (Fig. 8). Qualitatively it is already possible to observe in the chemical-state maps that the intensity of the BO signal is lower inside the contact area. Comparing the high-resolution spectra inside and outside the contact, the presence of a shorter-chain-length polyphosphate inside the tribotrack is supported by the lower $\mathrm{BO} / \mathrm{NBO}$ value and the chemical shift of the phosphorus peak. In Table 3 and Fig. 10 these results are compared with the data obtained from reference zinc polyphosphate glasses of different chain lengths. The observed depolymerization was very reproducible despite the inhomogeneous appearance of the tribotrack in the optical microscope, where it was possible to observe islands of material transferred from the ball to the disc. The iron signal due to this transfer film was detected inside the tribotrack and suggests the presence of a mixture of iron oxides and phosphates.

A reaction mechanism for the tribochemical reaction between iron oxide and zinc polyphosphates has been proposed by Martin [11]. According to the HSAB (hardand-soft acid-base) principle a hard base reacts preferentially with a hard acid and a soft base with a soft acid [10]. The formation of mixed zinc and iron glass is therefore the result of the reaction between the hard-base $\mathrm{PO}_{4}{ }^{3-}$ with the hard-acid $\mathrm{Fe}^{3+}$. As an example, the reaction between metaphosphate and iron(III)oxide is reported.

$5 \mathrm{Zn}\left(\mathrm{PO}_{3}\right)_{2}+\mathrm{Fe}_{2} \mathrm{O}_{3} \rightarrow \mathrm{Fe}_{2} \mathrm{Zn}_{3} \mathrm{P}_{10} \mathrm{O}_{31}+2 \mathrm{ZnO}$

This reaction could be activated by high shear stress and

\section{Disc after tribotest: compositional changes}

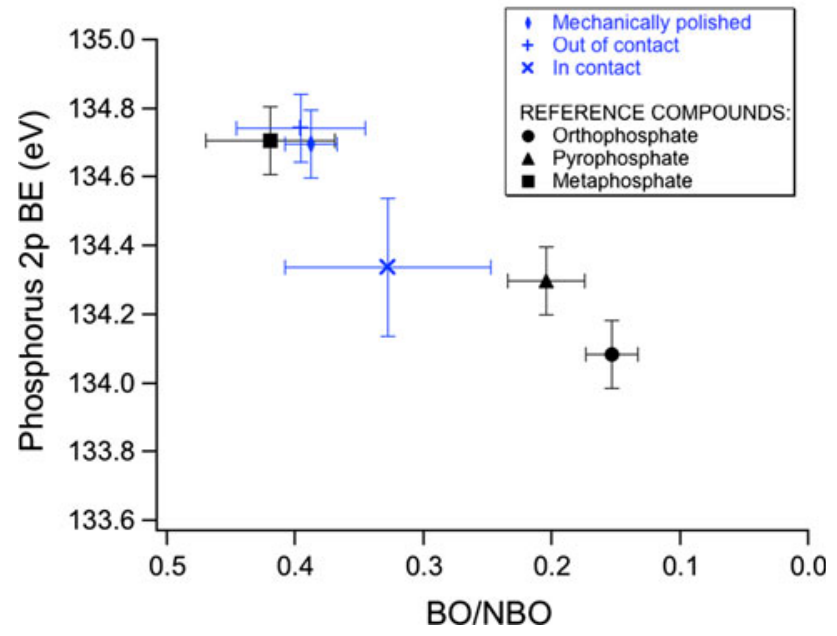

Fig. 10 BO/NBO versus $\mathrm{P} 2 \mathrm{p}_{3 / 2}$ BEs: comparison between reference and tribological samples would explain the shortening of the polyphosphate chain and the formation of iron phosphate. This reaction normally takes place only at high temperatures (above $1,300 \mathrm{~K})$. This means that enough energy has to be available for the reaction in the tribological system.

Moreover, since the mechanically polished samples showed a slight depolymerization compared to the samples in their initial state (see Table 3, Fig. 10), control experiments were carried out using quartz balls as inert tribopartners. These tribological tests were performed using exactly the same experimental conditions reported previously for the steel balls. The results showed no significant depolymerization for the $5 \mathrm{~N}$ tests, while at $7 \mathrm{~N}$ a slight depolymerization was present. Thus, it can be stated that the depolymerization of the glass can be caused not only by a chemical reaction with iron oxide or water, but can also occur as a consequence of high pressure and shear stress.

\subsection{Comparison with the Tribochemistry of ZnDTP Films}

The composition of the tribological films formed in the presence of ZnDTP is heterogeneous, with longer polyphosphate chain lengths being present in the outermost layer and a layer of shorter-chain-length polyphosphates at the bottom, which also contains zinc, iron, and some sulfur and unreacted/partially reacted additive adsorbed on the surface [8-10, 44]. Many parameters can influence the composition and the thickness of the tribofilms. For example, longer-chain-length films are obtained when alkyl ZnDTPs are used instead of their aryl counterparts [45]. Tribological stress is able to activate the degradation reactions of $\mathrm{ZnDTP}$ and the tribofilm is already formed at ambient temperatures [6], where only a weak interaction of the additive with the steel surface is present in the absence of mechanical stress. On the other hand, thermal films, formed on the metallic surface in a heated oil solution, show a different composition compared to the tribofilms and do not resist rubbing $[9,46]$. The tribofilms are, therefore, not only the result of a thermal degradation of the additive, but also of tribochemical reactions occurring at the interface between the lubricant and the steel surface, activated only by the sliding process. Temperature, pressure, composition, and degree of degradation of the additive also influence the chain length of the polyphosphate in the tribofilms.

A mechanism for the formation of a layered tribofilms involving the reaction between zinc polyphosphate and iron oxide has been proposed by Yin [3], but it has been very difficult to obtain any experimental evidence for these tribological reactions. Starting from fully formed $\mathrm{ZnDTP}$ tribofilms, Canning [9] has observed that long-chain polyphosphates convert to short-chain polyphosphates 
upon rubbing in base oil, as has also been found in the present study. It has also been proven that an increased contact pressure leads to the formation of tribofilms characterized by shorter chain lengths [8,9]. In this work, it has been shown that a long-chain phosphate glass is depolymerized as a consequence of sliding against steel. The reaction between zinc metaphosphate and iron oxide is activated by sliding and is more likely to take place on the ball surface, which undergoes the most severe mechanical stress. Moreover the tribological results have shown that the transfer film formed on the ball is able to reduce friction and prevent wear. The formation of a transfer film is common to many different tribological systems and it has been shown to be a very dynamic process [47]. The presence of an adhesive transfer film has also been found to correlate with the antiwear action in the case of ZnDTP [44] but more work is necessary, in order to establish whether the tribochemical reaction has a beneficial effect on the formation of the transfer film and its antiwear action.

\section{Conclusion}

From the data obtained in this work the following conclusions can be drawn:

- Polyphosphate glasses of different chain length have been synthesized and characterized. A protocol for tribological tests on the metaphosphate samples has been established.

- As a consequence of sliding against the zinc metaphosphate disc, a glassy transfer film is formed on the steel ball. In this area the chain length of the glass (calculated from the intensity ratio of the bridging and non-bridging oxygen signals $\mathrm{BO} / \mathrm{NBO}$ in the $\mathrm{O}$ 1s XPS peak) is lower (BO/NBO: 0.3) than that of the glass before the test (BO/NBO: 0.4 for the mechanically polished disc).

- The transfer film formed on the ball is able to reduce friction and prevent further wear on the ball.

- A depolymerization of the polyphosphate glass was observed in the tribotracks present on the zinc metaphosphate discs. The material transfer from the ball to the disc resulted in the presence of iron in the tribostressed area on the discs.

- A tribochemical reaction between zinc metaphosphate and iron oxide at the ball/disc interface has been proposed. This leads to the formation of iron phosphate and causes the depolymerization of the glass. The depolymerization of the glass can also occur as a consequence of high pressure and shear stress, and thus a synergy between chemical and physical effects cannot be excluded.
Acknowledgments The authors would like to thank the ETH Research Committee for its support of this work. Mr. M. Schneider kindly performed the microelemental analysis.

\section{References}

1. Spikes, H.: The history and mechanisms of ZDDP. Tribol. Lett. 17, 469-489 (2004)

2. Barnes, A.M., Bartle, K.D., Thibon, V.R.A.: A review of zinc dialkyldithiophosphates (ZDDPS): characterisation and role in the lubricating oil. Tribol. Int. 34, 389-395 (2001)

3. Yin, Z., Kasrai, M., Fuller, M., Bancroft, G.M., Fyfe, K., Tan, K.H.: Application of soft X-ray absorption spectroscopy in chemical characterization of antiwear films generated by ZDDP Part I: the effects of physical parameters. Wear 202, 172-191 (1997)

4. Martin, J.M., Grossiord, C., Le Mogne, T., Bec, S., Tonck, A.: The two-layer structure of ZnDTP tribofilms: part I: AES, XPS and XANES analyses. Tribol. Int. 34, 523-530 (2001)

5. Gellman, A., Spencer, N.D.: Surface chemistry in tribology. Proc. Inst. Mech. Eng. J. 216, 443-461 (2002)

6. Eglin, M., Rossi, A., Spencer, N.D.: X-ray photoelectron spectroscopy analysis of tribostressed samples in the presence of ZnDTP: a combinatorial approach. Tribol. Lett. 15, 199-209 (2003)

7. Heuberger, R., Rossi, A., Spencer, N.D.: XPS study of the influence of temperature on ZnDTP tribofilm composition. Tribol. Lett. 25, 185-196 (2007)

8. Heuberger, R., Rossi, A., Spencer, N.D.: Pressure dependence of ZnDTP tribochemical film formation: a combinatorial approach. Tribol. Lett. 28, 209-222 (2007)

9. Canning, G.W., Suominen Fuller, M.L., Bancroft, G.M., Kasrai, M., Cutler, J.N., De Stasio, G., Gilbert, B.: Spectromicroscopy of tribological films from engine oil additives. Part I. Films from ZDDP's. Tribol. Lett. 6, 159-169 (1999)

10. Pearson, R.G.: Chemical Hardness. Wiley, New York (1997)

11. Martin, J.M.: Antiwear mechanisms of zinc dithiophosphate: a chemical hardness approach. Tribol. Lett. 6, 1-8 (1999)

12. Minfray, C., Le Mogne, T., Martin, J.M., Onodera, T., Nara, S., Takahashi, S., Tsuboi, H., Koyama, M., Endou, A., Takaba, H., Kubo, M., Del Carpio, C.A., Miyamoto, A.: Experimental and molecular dynamics simulations of tribochemical reactions with ZDDP: zinc phosphate-iron oxide reaction. Tribol. Trans. 51, 589-601 (2008)

13. Mosey, N.J., Woo, T.K., Kasrai, M., Norton, P.R., Bancroft, G.M., Müser, M.H.: Interpretation of experiments on ZDDP antiwear films through pressure-induced cross-linking. Tribol. Lett. 24, 105-114 (2006)

14. Gauvin, M., Dassenoy, F., Belin, M., Minfray, C., Guerret-Piecourt, C., Bec, S., Martin, J.M., Montagnac, G., Reynard, B.: Boundary lubrication by pure crystalline zinc orthophosphate powder in oil. Tribol. Lett. 31, 139-148 (2008)

15. Sunnegardh-Gronberg, K., Peutzfeldt, A., van Dijken, J.W.V.: Hardness and in vitro wear of a novel ceramic restorative cement. Eur. J. Oral Sci. 110, 175-178 (2002)

16. Abou Neel, E.A., Pickup, D.M., Valappil, S.P., Newport, R.J., Knowles, J.C.: Bioactive functional materials: a perspective on phosphate-based glasses. J. Mater. Chem. 19, 690-701 (2009)

17. Baikova, L., Pukh, V., Fedorov, Y., Sinani, A., Tikhonova, L., Kireenko, M.: Mechanical properties of phosphate glasses as a function of the total bonding energy per unit volume of glass. Glass Phys. Chem. 34, 126-131 (2008)

18. Tischendorf, B., Otaigbe, J.U., Wiench, J.W., Pruski, M., Sales, B.C.: A study of short and intermediate range order in zinc phosphate glasses. J. Non-Cryst. Solids 282, 147-158 (2001) 
19. Brow, R.K., Tallant, D.R., Myers, S.T., Phifer, C.C.: The shortrange structure of zinc polyphosphate glass. J. Non-Cryst. Solids 191, 45-55 (1995)

20. Wazer, J.R.V.: Phosphorus and its Compounds. Interscience, New York (1958)

21. Corbridge, D.E.C.: Phosphorus. An Outline of its Chemistry Biochemistry and Technology. Elsevier, Amsterdam (1990)

22. Hoppe, U., Walter, G., Carl, G., Neuefeind, J., Hannon, A.C.: Structure of zinc phosphate glasses probed by neutron and X-ray diffraction of high resolving power and by reverse Monte Carlo simulations. J. Non-Cryst. Solids 351, 1020-1031 (2005)

23. Musinu, A., Piccaluga, G.: An X-ray diffraction study of the short-range order around $\mathrm{Ni}(\mathrm{II}), \mathrm{Zn}(\mathrm{II})$ and $\mathrm{Cu}(\mathrm{II})$ in pyrophosphate glasses. J. Non-Cryst. Solids 192-193, 32-35 (1995)

24. Musinu, A., Piccaluga, G., Pinna, G., Narducci, D., Pizzini, S.: Short-range order of $\mathrm{Zn}$ and $\mathrm{Cu}$ in metaphosphate glasses by X-ray diffraction. J. Non-Cryst. Solids 111, 221-227 (1989)

25. Bionducci, M., Licheri, G., Musinu, A., Navarra, G., Piccaluga, G., Pinna, G.: The structure of a Zn(II) metaphosphate glass. 1 . The cation coordination by a combination of X-ray and neutron diffraction, EXAFS and X-ray anomalous scattering. J. Phys. Sci. 51, 1209-1215 (1996)

26. Lai, A., Musinu, A., Piccaluga, G., Puligheddu, S.: Structural evolution in zinc and lead phosphate glasses by $\mathrm{X}$-ray diffraction and P MAS NMR spectroscopy. Phys. Chem. Glasses 38, 173178 (1997)

27. Sales, B.C., Otaigbe, J.U., Beall, G.H., Boatner, L.A., Ramey, J.O.: Structure of zinc polyphosphate glasses. J. Non-Cryst. Solids 226, 287-293 (1998)

28. Wiench, J.W., Tischendorf, B., Otaigbe, J.U., Pruski, M.: Structure of zinc polyphosphate glasses studied by two-dimensional solid and liquid state NMR. J Mol. Struct. 602, 145-157 (2002)

29. Gresch, R., Müller-Warmuth, W., Dutz, H.: X-ray photoelectron spectroscopy of sodium phosphate glasses. J. Non-Cryst. Solids 34, 127-136 (1979)

30. Arens, C.M., Brow, R.K.: An XPS study of iron phosphate glasses. Phys. Chem. Glasses 35, 132-199 (1993)

31. Brow, R.K.: An XPS study of oxygen bonding in zinc phosphate and zinc borophosphate glasses. J. Non-Cryst. Solids 194, 267273 (1996)

32. Yin, Z.F., Kasrai, M., Bancroft, G.M., Tan, K.H., Feng, X.H.: $\mathrm{X}$-ray-absorption spectroscopic studies of sodium polyphosphate glasses. Phys. Rev. B 51, 742-750 (1995)

33. Seah, M.P.: Quantification of AES and XPS. In: Briggs, D., Seah, M.P. (eds.) Practical Surface Analysis, pp. 201-255. Wiley, Sussex (1990)
34. Scofield, J.H.: Hartree-Slater subshell photoionization cross-sections at 1254 and $1487 \mathrm{eV}$. J. Electron. Spectrosc. 8, 129-137 (1976)

35. Reilman, R.F., Msezane, A., Manson, S.T.: Relative intensities in photoelectron-spectroscopy of atoms and molecules. J. Electron. Spectrosc. 8, 389-394 (1976)

36. Tanuma, S., Powell, C.J., Penn, D.R.: Calculations of electron inelastic mean free paths V. Data for 14 organic compounds over the 50-2000 eV range. Surf. Interface Anal. 21, 165-176 (1994)

37. Efimov, A.M.: IR fundamental spectra and structure of pyrophosphate glasses along the $2 \mathrm{ZnO}$ center dot $\mathrm{P}_{2} \mathrm{O}_{5}-2 \mathrm{Me}(2) \mathrm{O}$ center dot $\mathrm{P}_{2} \mathrm{O}_{5}$ join (Me being $\mathrm{Na}$ and $\mathrm{Li}$ ). J. Non-Cryst. Solids 209, 209-226 (1997)

38. Meyer, K.: Characterization of the structure of binary zinc ultraphosphate glasses by infrared and Raman spectroscopy. J. Non-Cryst. Solids 209, 227-239 (1997)

39. Rulmont, A., Cahay, R., Liegeoisduyckaerts, M., Tarte, P.: Vibrational spectroscopy of phosphates-some general correlations between structure and spectra. Eur. J. Solid State Inorg. Chem. 28, 207-219 (1991)

40. Velli, L.L., Varsamis, C.P.E., Kamitsos, E.I., Moncke, D., Ehrt, D.: Structural investigation of metaphosphate glasses. Phys. Chem Glasses 46, 178-181 (2005)

41. Cloots, R., Rulmont, A., Godelaine, P.A., Hannay, C., Vanderschueren, H.W., Ausloos, M.: Sulfur substitution for oxygen in $\mathrm{YBA}_{2} \mathrm{Cu}_{3} \mathrm{O}_{7}$ ceramics. Solid State Commun. 79, 615-619 (1991)

42. Onyiriuka, E.C.: Zinc phosphate glass surfaces studied by XPS. J. Non-Cryst. Solids 163, 268-273 (1993)

43. Piras, F.M., Rossi, A., Spencer, N.D.: Combined in situ (ATR FT-IR) and ex situ (XPS) study of the ZnDTP-iron surface interaction. Tribol. Lett. 15, 181-191 (2003)

44. Minfray, C., Le Mogne, T., Lubrecht, A.A., Martin, J.M.: Experimental simulation of chemical reactions between ZDDP tribofilms and steel surfaces during friction processes. Tribol. Lett. 21, 67-78 (2006)

45. Fuller, M., Yin, Z., Kasrai, M., Bancroft, G.M., Yamaguchi, E.S., Ryason, P.R., Willermet, P.A., Tan, K.H.: Chemical characterization of tribochemical and thermal films generated from neutral and basic ZDDPs using X-ray absorption spectroscopy. Tribol. Int. 30, 305-315 (1997)

46. Bancroft, G.M., Kasrai, M., Fuller, M., Yin, Z., Fyfe, K., Tan, K.H.: Mechanisms of tribochemical film formation: stability of tribo- and thermally-generated ZDDP films. Tribol. Lett. 3, 47-51 (1997)

47. Scharf, T.W., Singer, I.L.: Monitoring transfer films and friction instabilities with in situ Raman tribometry. Tribol. Lett. 14, 3-8 (2003) 